\title{
Supplementary private health insurance: the impact of physician financial incentives on medical practice
}

\author{
Carine MILCENT ${ }^{*}$ and Saad ZBIRI ${ }^{\S}$
}

\begin{abstract}
In the French DRG-based payment system, both private and public hospitals are financed by a public single-payer. Public hospitals are overcrowded and have no direct financial incentives to choose one procedure over another. If a patient has a strong preference, they can switch to a private hospital. In private hospitals, the preference does come into play, but the patient has to pay for the additional cost, for which they are reimbursed if they have supplementary private health insurance. Do financial incentives from the fees received by physicians for different procedures drive their behavior? Using French exhaustive data on delivery, we find that private hospitals perform significantly more cesarean deliveries than public hospitals. However, for patients without private health insurance, the two sectors differ much less in terms of cesareans rate. We determine the impact of the financial incentive for patients who can afford the additional cost. Affordability is mainly ensured by the reimbursement of costs by private health insurance. These findings can be interpreted as evidence that, in healthcare systems where a public single-payer offers universal coverage, the presence of supplementary private insurance can contribute to creating incentives on the supply side and lead to practices and an allocation of resources that are not optimal from a social welfare perspective.
\end{abstract}

JEL classification: I11, I12, I13, I18

Keywords: Supplementary private health insurance; Physician financial incentives; Public healthcare system; DGR-based payment; Cesarean delivery.

\footnotetext{
"We are grateful to Patrick Rozenberg, obstetrician director of the local perinatal network of the Yvelines (MYPA) which includes all hospitals providing obstetrics services in the district, for access to data and helpful support. We also thank the physicians and midwives of MYPA network for their support.

\$ Paris-Jourdan Sciences Economiques, French National Center for Scientific Research, Paris, France. E-mail address: carine.milcent@psemail.eu

$\S$ EA 7285, Versailles Saint Quentin University, Montigny-le-Bretonneux, France. E-mail address: saad.zbiri3@uvsq.fr
} 


\section{Introduction}

In this paper, we identify physicians' responses to financial incentives. We investigate the impact of private health insurance on a hospital healthcare system in which both the public and the private sectors are publicly funded in what appears to be a similar manner. In a first step, we determine the extent to which private and public hospitals differ in terms of the rate of cesareans performed. We then show that this difference decreases as the financial capacity of women to afford a cesarean (and respond to inducement) reduces, ultimately vanishing entirely for women with the lowest economic status. Throughout the study, we focus on women with low clinical risk.

Activity-based payment using diagnosis-related groups (DRGs) has become commonplace in most developed countries. The majority of the literature to date, both theoretical and empirical, has examined the overall effect of activity-based payment on cost efficiency and hospital performance (Hafsteinsdottir and Siciliani, 2010). Although convincing theoretical arguments have led to expectations of hospital cost reduction and improved efficiency, the empirical evidence is inconclusive. The introduction of the DRG system has been associated with positive effects on hospital efficiency in Finland (Linna, 1999), Portugal (Dismuke and Sena, 1999), Norway (Biørn et al., 2003; Biørn et al., 2010), and Switzerland (Widmer, 2015), while no such effects have been found for Germany (Herwartz and Strumann, 2014), Italy (Barbetta et al., 2007), Austria (Sommersguter-Reichmann, 2000), and the United States (Borden, 1988; Chern and Wan, 2000).

As far as France is concerned, all public and private hospitals are publicly funded through a DRG-based ${ }^{1}$ prospective payment system that became broadly implemented in 2008 . For public hospitals, France has a model whereby hospitals compete with each other, but the physicians are salaried. For private hospitals, both the hospitals themselves as well as the physicians are paid according to their level of activity, but they also receive additional payments when patients have private health insurance. For obstetric activity, performing a cesarean delivery is associated with a substantial additional payment. This raises the question of doctors' profit-oriented practices. Baker et al. (2014) examined the consequences of contractual or ownership relationships between hospitals and physician practices, which is often described as vertical integration. They found that "an increase in the market share of

\footnotetext{
${ }^{1}$ A specific DRG classification has been implemented in France. For simplicity, the term "DRG" will be used as a generic term that includes the French classification.
} 
hospitals with the tightest vertically integrated relationship with physicians - ownership of physician's practices - is associated with higher hospital prices and spending". A systematic review examining the factors explaining the diversity of findings regarding hospital ownership and quality (Eggleston et al., 2008) reported that the diverse results regarding hospital ownership can largely be explained by differences in the institutional context, including differences across regions and markets, and over time.

Most of the empirical work to date on the effect of reimbursement rules on healthcare production has used data from the USA (see Sloan, 2000 for a review). However, the structure of the USA healthcare market makes it hard to disentangle the pure effect of hospital ownership from other institutional features such as the segmentation of insurance or payers and payment types (Lien et al., 2008). In France, the national health insurance system (Sécurite Sociale) is a single-payer system that covers the entire population. Studying the French context effectively eliminates any concern about different reimbursement schemes for different payers, negotiation between providers and payers, and cost-shifting behavior by providers on the supply side and financial access to hospitals on the demand side.

Controlling for the relevant patient- and hospital-level characteristics, we find that private hospitals perform more cesarean deliveries than public sector hospitals. This result is robust to restricting the sample to the women with low clinical risk. It is also consistent with the stronger financial incentives of physicians in private hospitals, and with the fact that the context in these institutions is likely to offer physicians more flexibility to respond to incentives. Indeed, while both sectors are publicly funded, private sector hospitals and doctors receive additional payments from private health insurance for fees that public hospitals are not allowed to charge. ${ }^{2}$ Moreover, women who choose a private hospital also choose their physician and they can have a say in how they give birth. In the public sector, the pregnancy is monitored by a team instead of by a specific doctor. In addition, in the absence of complications, the woman is monitored by midwives, including during labor. Midwives decide whether to call a doctor both before and during labor.

In this study, we compare the setup (private hospitals) in which physicians are subject to financial incentives with another setup (public hospitals) where these do not apply because the physicians are on fixed salaries only. In a second empirical step, we bypass a potential

\footnotetext{
${ }^{2}$ More details are presented in Section 2.2.
} 
selection effect of agents across hospital sectors: we compare the cesarean rates between feefor-service physicians (private sector) and physicians on fixed salaries when they treat patients for whom there is no financial incentive (patients without private health insurance) versus the difference in cesarean rates when they treat patients for whom only fee-for-service doctors have a financial incentive to perform a cesarean (patients with private health insurance).

Do financial incentives from the fees paid to physicians for different procedures drive their behavior? Using French exhaustive delivery data, we find that private hospitals perform significantly more cesarean deliveries than public hospitals. However, for patients without private health insurance, the two sectors differ much less in terms of the number of cesareans performed. We determine the impact of the financial incentive for patients who can afford the additional cost. Affordability is mainly ensured by the reimbursement of costs by private health insurance.

In the following section, we briefly outline the factors that determine the use of cesarean delivery and, after providing an overview of the characteristics of French hospitals, their incentives to provide obstetric services. The third section describes the data used for this study and provides some preliminary statistics. The econometric strategy is presented in the fourth section, and the results and robustness checks are reported in the fifth section. In the sixth section, we discuss the results and we provide a conclusion regarding our findings.

\section{Cesarean delivery and incentives for cesarean delivery in the French healthcare system}

\subsection{Use of cesarean deliveries}

Cesarean delivery is one of the most common surgical procedures performed worldwide (Gibbons et al., 2012). Epidemiologic studies have revealed a negative association between cesarean rates and maternal, neonatal, and infant morbidity and mortality (Althabe et al., 2006; Villar et al., 2007). Although cesarean delivery can provide a degree of psychological and social well-being (Mazzoni et al., 2011), it can also cause significant and sometimes permanent complications, disability, or death (Hyde and Modi, 2012; Souza et al., 2010). It is also associated with a higher cost (Allen et al., 2005; Rogers et al., 2017). Cesarean delivery should, therefore, only be undertaken when medically necessary. The research literature has 
identified many interrelated factors that influence the number of cesarean deliveries. These are related to the characteristics of the women who are pregnant, the medical staff, and the hospitals.

The characteristics of the women in part explain the use of cesarean deliveries. Older women and those having their first child have a higher probability of cesarean delivery (Cleary et al.,1996; Ecker et al., 2001). The presence of certain medical risk factors for the woman and/or her fetus, which may arise from conditions that existed before the pregnancy (e.g., a chronic disease), or that develop during the pregnancy (e.g., eclampsia), or labor (e.g., dystocia), are associated with a higher rate of cesarean births (Menacker et al., 2006; Penn and Ghaem-Maghami, 2001). Furthermore, women with a lower socioeconomic status have a higher probability of cesarean delivery than their more socioeconomically advantaged counterparts, at least in high-income countries (Linton et al., 2004; Milcent and Zbiri, 2018); while the woman's preference may also be a factor (Mazzoni et al., 2011).

The time required to perform a cesarean is relatively uniform for a planned cesarean, while the time required for a vaginal delivery is unpredictable. Managing the medical equipment and the facilities as well as the physician's time is, therefore, easier with a cesarean delivery. The probability of a cesarean delivery has been shown to increase sharply on Friday evenings and it decreases during weekends as physicians factor their time off into their medical practices (Brown, 1996; Fabbri, 2008).

The heterogeneity of delivery practices may also be explained in part by hospital characteristics. An increased likelihood of cesarean deliveries has been reported for wellequipped hospitals (Le Ray et al., 2006) as well as for teaching hospitals (Hammond, 2015). Hospital organization also plays a role. For example, the probability of cesarean delivery is lower in hospitals in which the obstetricians are more available (Yee et al., 2017). The size of the maternity ward also affects the probability of cesarean delivery in various ways (Roman et al., 2008; David et al., 2001). Staff organization in hospitals also has an impact (Zbiri et al., 2018).

Finally, hospital and physician financial incentives affect the cesarean delivery rate. Gruber and Owings (1996) reported that, after a drop in the birth rate in some states in the USA, the number of cesarean deliveries increased. Gruber et al. (1999) showed that a significant pay gap between a cesarean and a vaginal delivery accounts for half of the differences in practices 
in the USA. Using the data from Gruber et al., Grant (2009) confirmed the effect of physicians' financial incentives on cesarean rates. Recently, Allin et al. (2015) reported that increasing the fee differential between cesarean and normal delivery in Canada led physicians to perform more cesareans. In France, Milcent and Rochut (2009), using data from before the implementation of the activity-based payment system, showed that private for-profit hospitals performed substantially more cesarean deliveries than public-sector hospitals. This disparity was attributed to the difference in hospital payment systems. This context has changed, however, as all French hospitals are now governed by the same reimbursement rules for all acute care stays, including for childbirth.

\subsection{Incentives for cesarean delivery}

French hospital healthcare is based on a single-payer system: the national health insurance funds (Sécurité Sociale). In the public sector, the doctors' wages are based on the civil servant remuneration scale, while in the private sector, independent physicians work on a fee-forservice basis, charging their patients directly. As a result, there are two fee scales according to the sector. These are presumably nearly equivalent once the private obstetrician has billed the patient separately for their services. Table A1 presents the fee as a function of the hospital sector for the first and the last year of the study period. It can be seen that the mean DRG fee for delivery is around 2,500 Euros. This fee is approximately $40 \%$ higher for a cesarean delivery than for a vaginal delivery, and the difference in these fees is quite similar irrespective of the sector. Hence, based on the DRG fee, the differences between a delivery with or without a cesarean provide the same incentive in both sectors for the organization, but the incentives are different for the obstetricians, as they can charge above and beyond the reimbursed fee schedule.

However, the situation is somewhat more complex. Only in private hospitals can patients be charged additional fees for (1) room and board, and (2) physicians' fees. ${ }^{3}$ The room and board fees can be substantial in private hospitals. They are typically between 100 and 250 Euros for a one-night stay and may hence encourage medical practices that optimize the length of stay. Cesareans require longer hospitalizations than vaginal deliveries. A private hospital, therefore, has an additional incentive to perform more cesarean deliveries.

\footnotetext{
${ }^{3}$ At present, public hospitals are allowed to charge an additional fee for a room, provided it is a single room. Note that these amounts are usually quite low compared what private hospitals charge (usually an average of 50 Euros).
} 
The hospital sector also affects the physician's income. In France, physicians, including obstetricians, can split their time between activities in the private and in the public sector. In the public sector, hospitals compete both within and across sectors. On the other hand, the medical staff and the doctors are salaried. Their volume of work activity does not affect their income. As a result, the doctor's choice of procedure is not influenced by income considerations. The doctor is a limiting factor in the push for greater volumes. In the private sector, physicians charge mainly on a fee-for-service basis. They submit their fees directly to the health fund and to the patient, which is sometimes managed for them by the hospital. Moreover, they pay back a portion of their fees to the private hospital to pay for access to beds and operating/delivery rooms as well as other hospital facilities. All these aspects are specified in the contract between the physician and the private hospital. These payment practices are not subject to strict official regulations. For obstetric activity, most of the additional payment is for cesarean delivery, and only when the physician is physically present during the delivery process. The supplementary fees earned directly by the practitioner vary from 150 to 2,700 Euros, with a mean of 900 Euros. For anesthetists, the regular fee is approximately 300 Euros. $^{4}$ As in the USA, both the doctor and the hospital administration in the French private sector have incentives to increase the volume of cesareans.

In addition to the financial incentive, cesarean deliveries allow obstetricians to better schedule their work commitments, thereby potentially increase volumes as well as allowing deliveries to be carried at different facilities.

Obstetricians at private hospitals are also more likely to practice defensive medicine, and cesarean deliveries may reduce their exposure to malpractice liability because they reduce the risk of complications during delivery. More importantly, physicians at public hospitals are covered by the hospital's malpractice liability insurance, while independent physicians in private hospitals have to purchase their own malpractice insurance, which costs about 30,000 Euros per year for a full-time private-sector obstetrician. This may be an incentive to perform more planned cesarean deliveries, as the medical risk for these is lower. Moreover, in case of complications in labor, they have greater incentives to avoid these by undertaking a cesarean procedure. The apparent increased use of "defensive medicine" in obstetrics is likely to be a contributing factor in the increase in cesarean deliveries. Many studies have found a positive correlation between higher cesarean rates and the increase in the risks perceived by

\footnotetext{
${ }^{4}$ Unpublished health insurance data from 2011 and on the Ministry of Health website from 2014: https://www.scansante.fr/accueil
} 
obstetricians regarding complaints and litigation (Fuglenes et al., 2009) or in their malpractice insurance premiums (Dubay et al., 1999; Yang et al., 2009).

What about the patient's choice of physician? In public hospitals, patients generally do not choose their physician. They are assigned according to the catchment area for a specific hospital but not to a specific obstetrician. During pregnancy, a woman may be under the care of different physicians or even only/mainly midwives for her prenatal care visits. When a planned cesarean delivery is scheduled, this decision is made as a collective decision by the medical team. When a normal delivery is scheduled, the midwife is the person who decides whether to call the obstetrician for an urgent cesarean delivery. In a private hospital, on the other hand, the patient can choose a specific obstetrician, who then generally provides all of her prenatal care in addition to performing the delivery. During the prenatal period, a woman has time to develop a high level of trust in her obstetrician. When she does not feel confident with her initial choice, she has enough time to switch to another obstetrician. The patientphysician relationship is hence closer, which increases the likelihood that the obstetrician will be able to satisfy the woman's requests regarding the delivery. If the woman has a preference for a cesarean delivery, the obstetrician will give due consideration to her preference. Yet, the obstetrician may prefer a cesarean rather than a vaginal delivery based on factors such as those presented in Figure 1, which may or may not include clinical factors. Their close relationship with their patients, established during the prenatal period, can help them steer their patients to what they consider to be the most appropriate medical treatment and approach to the pregnancy and the delivery.

While we do not have the capacity to directly disentangle hospital and physician responses to financial incentives, as they both occur in the private sector, our identifying strategy, exploiting the differences in coverage between those who have and do not have private insurance, supports the notion that the differences in cesarean rate between patients treated in private versus public hospitals are at least partly due to the physicians' responses to financial incentives.

\section{[Insert Figure 1]}

What is the impact on patient access to healthcare? In France, all households have compulsory public health insurance, which is financed by deductions (or for the selfemployed, mandatory contributions) as a percentage of their income. In-patient obstetric 
services (delivery) are fully reimbursed, irrespective of the hospital sector. For the small proportion of people who are not covered by the public health insurance system because no one in the household is employed, a special fund of the public health insurance system (CMUC) provides the equivalent of $100 \%$ coverage for childbirth. Therefore, the healthcare reimbursement for admissions in either a public or a private hospital comes from this public single-payer health insurer. However, this reimbursement does not include reimbursement for the additional fees. This is where supplementary private insurance plays an important role. Depending on the level of insurance, these fees will be fully covered, partially covered, or not covered at all.

Although $95 \%$ of the French population has this type of supplementary private health insurance (Ministry of Health, 2016), the level of reimbursement for these additional fees depends on the private supplementary health insurance premium. For patients with a low level of private insurance, these additional fees are often not or poorly reimbursed. For very financially disadvantaged women (covered by the so-called CMU-C), there is no additional fee at for-profit hospitals. Most of the time, these patients go directly to a public hospital, mainly when a cesarean is scheduled. However, defined by law as a right to healthcare access, the private sector has to admit a certain percentage of these very financially disadvantaged women. The direct referral of low-income women to a private hospital is mainly driven by local supply; i.e., when the public sector does not have the capacity to cater to the local demand. In any case, for these individuals, there are no additional fees when a cesarean is performed.

\section{Data and preliminary statistics}

We exclusively used French data that allow us to consider the factors that influence cesarean deliveries, including $i$ ) the woman's age and medical risk factors, ii) her household's socioeconomic situation, and iii) hospital characteristics, including the sector and the organization of the maternity unit.

\subsection{Exhaustive delivery data}

We used data from deliveries from 2008 through 2014 from two databases. One of these databases contains information regarding all deliveries in the Yvelines department. The Yvelines department is one of the four administrative districts of the outer suburbs of the 
greater Paris region. The Yvelines administrative district has a population (1.5 million inhabitants) comparable to that of the state of New Hampshire in the USA. The second database (Statistique Annuelle des Etablissements de santé, SAE) contains information about all French hospitals. ${ }^{5}$

\subsection{Descriptive statistics}

All of the hospitals are located in urban areas: There is a mix of private and public hospitals in both high- and low-income areas. ${ }^{6}$ As shown in Table A2, only a small proportion of the women do not have a partner (2\%). The majority of the women $(61.4 \%)$ have a postsecondary education. ${ }^{8}$ Most of the women and their partners are employed, at $69.6 \%$ and $89.8 \%$, respectively, versus $6.7 \%$ and $4.4 \%$, respectively, who are unemployed, and $23.7 \%$ and $5.8 \%$, respectively, who are not in the labor force. ${ }^{9}$ There are also differences in the types of jobs held. Both the women and their partners most often have an office, sales, or service sector job (55.2\% and $40.1 \%$, respectively) followed by managerial and higher intellectual positions ( $31 \%$ and $36.7 \%$, respectively).

The Yvelines administrative district is well served by healthcare facilities that provide obstetric care. There are 11 hospitals, 5 of which are public hospitals and 6 private hospitals. All of the private hospitals in the Yvelines department are private for-profit hospitals. From 2008 through 2014, the number of deliveries remained stable, accounting for $13 \%$ of the annual deliveries nationwide (SAE, 2008-2014 data). In this district, 66.4\% of the deliveries took place in public hospitals and $33.6 \%$ in private hospitals. The distribution of births by sector was similar to the nationwide distribution. ${ }^{10}$ Maternity units without special neonatal care (equipment level 1, with the least equipment) accounted for $19.1 \%$ of the deliveries, versus $39.6 \%$ and $41.3 \%$ for hospitals with special or intensive neonatal care units, respectively. Moreover, university hospitals performed $37.5 \%$ of the deliveries in the district.

\footnotetext{
${ }^{5}$ More details regarding the databases used are available in the Appendix.

${ }^{6}$ A low income is defined as less than 20,000 Euros, which is the median personal income in France (INSEE, 2008-2014 data).

${ }^{7}$ Table A2 is available in the Appendix with additional comments.

${ }^{8}$ In contrast to those with some secondary schooling, the women who completed secondary education reached the final year of secondary school, whether or not they obtained a baccalaureate degree.

${ }^{9}$ Those not in the labor force included students, apprentices, homemakers, retirees, individuals on parental leave, and others neither working nor looking for employment.

${ }^{10}$ In France, $66 \%$ and $34 \%$ of deliveries were performed in public and private hospitals, respectively (SAE, 2008-2014 data).
} 
The population characteristics vary considerably according to the hospital sector (Table A2). The women giving birth in private hospitals are older than those in public hospitals (31.5 versus 30.3 years, respectively). Nonetheless, public hospitals provide care for a population considered to be at higher risk than those in private hospitals. For example, $4.3 \%$ of the women giving birth in public hospitals have diabetes versus $3.3 \%$ of those admitted to private hospitals.

Similarly, the economic level of the households affects the sector: the percentages of loweducated, low-skilled, and unemployed women are all higher in public than in private hospitals, at $42.8 \%$ versus $30.5 \%, 60.4 \%$ versus $49.3 \%$, and $32.8 \%$ versus $25.5 \%$, respectively. The same disparities are noted for the partners: in public hospitals, with $55.7 \%$ and $11.7 \%$ of the parturients' partners being low-skilled workers or unemployed, respectively, compared to $39.3 \%$ and $11.7 \%$, respectively, in private hospitals.

When we compare the equipment level by sector, we observe that the majority of births in public hospitals take place in well-equipped maternity wards capable of providing neonatal intensive care $(62.2 \%)$, while in private hospitals the women most often give birth in maternity wards capable of providing special neonatal care $(60 \%)$. Of note, all of the hospitals with neonatal intensive care units and all of the teaching hospitals are public entities. ${ }^{11}$

\section{Econometric strategy}

The empirical analysis used panel data to assess the effect of the hospital sector on the practice of cesarean deliveries.

A simplified way of expressing the basic model that we devised is as follows:

$$
P\left(Y_{i j t}\right)=f\left(T_{t}, D_{i j t}, X_{i j t}, S_{i j t}, V_{i j t}, W_{i j} / e_{i j t}\right)
$$

with $Y$ equals 1 if woman $i$ in hospital $j$ in year $t$ has a cesarean.

\footnotetext{
${ }^{11}$ In France, the hospitals with a neonatal intensive care unit are all in the public sector. Moreover, any institution with an intensive care unit would be required to accept emergency cases, which could explain the absence of any private neonatal intensive care units.
} 
- $T_{t}$ is a linear continuous-time variable (trend), starting in $2008($ trend $=0)$ and ending in 2014 $($ trend $=6) ;^{12}$

- $D_{i j t}$ is the set of variables of demographic characteristics for patient $i$ in hospital $j$ in year $t$ : age and parity;

- $X_{i j t}$ is the set of medical risk factors of woman $i$ in hospital $j$ in year $t$ such that one of them justifies or favors performing a cesarean delivery: previous cesarean, diabetes, hypertension, eclampsia or preeclampsia (including HELLP syndrome), intrauterine growth restriction, placental disorder (including placenta previa, placenta accreta, and abruptio placenta), other obstetric pathology (such as obesity, infection, premature rupture of membranes, amniotic fluid abnormality, or congenital anomaly), multiple pregnancy, preterm delivery (gestational age $<37$ weeks), post-term delivery (gestational age $>41$ weeks), fetal breech presentation or transverse lie, induced labor, low birth weight $(<2,500$ grams $)$, and high birth weight $(>4,000$ grams);

- $S_{i j t}$ is the set of variables for the socioeconomic characteristics for patient $i$ in hospital $j$ in year $t$ : status of the couple, the woman's level of education, type of job, employment status, (rural) location, and her partner's type of job and employment status;

- $V_{i j t}$ is the set of variables regarding hospital organization: the 24-hour availability of obstetricians for hospital $j$ in year $t$, the day of delivery for woman $i$ in hospital $j$ in year $t$, the size of the unit based on the volume of deliveries of hospital $j$ in year $t$, and the numbers of midwives, obstetricians, and anesthetists working at hospital $j$ in year $t$, as measured by fulltime equivalent (FTE) employees per occupied patient bed; ${ }^{13}$

- $W_{j t}$ is the set of hospital type variables for hospital $j$ in year $t$ : sector, equipment level, and university status;

- $e_{i j t}$ is the error term.

\footnotetext{
${ }^{12}$ Considering a full set of time dummy variables instead of a trend variable did not change the results.

${ }^{13}$ The amount of time independent private practitioners spend on their hospital practice is not known. As a result, we suggest that part-time private practice doctors work $50 \%$ of the time at the hospital, and thus represent $50 \%$ of an FTE. This standard assumption is widely used (Clark and Milcent, 2011; Zbiri et al., 2018). While this is perhaps reasonable, we also checked that all our results were robust to the more extreme assumptions of $25 \%$ and $75 \%$ of an FTE (see Section 5.4).
} 
We used hierarchical data: patients grouped by their hospital. We estimated multilevel logit models with a robust variance that takes the lack of independence between observations at the hospital level into account. The Hausman specification test between the specifications of the hospital fixed-effects and the hospital random-effects resulted in accepting the null hypothesis ( $\mathrm{p}$-value $>0.10)$. The hospital random-effects model thus produced consistent and efficient estimations: the hospital's characteristics not explicitly taken into account in the model are not correlated with any independent variables. ${ }^{14}$

Studies in the field of obstetrics face an important estimation issue, namely preferences (Figure 1). Preferences play a role in determination of the type of delivery - both the preference of the woman and of the doctor. There is a degree of heterogeneity in both sets of preferences, and this is likely to affect the type of delivery. Physicians' preferences depend on various clinical characteristics of the woman and on aspects of the physicians' practice characteristics, risk aversion, especially in relation to complications and malpractice as well as financial incentives. We then compare a subsample of low-risk women with a subsample of high-risk women. This allows us to disentangle the clinical aspect in physician's decisions from the other aspects.

The woman's preference for the mode of delivery can also influence the physician's decision. In the private sector, the woman's preference matters. If a woman has a preference as to how she gives birth, then it is likely that this will impact the physician's decision. According to Figure 1, from the database, we observe the result of a combination of the woman's preference and the physician's preference added to other components. In the French public sector, the woman's preference has no impact. Public hospitals are overcrowded, and physicians have no direct financial incentives to choose one procedure over another. Women do not choose their physician, even with a cesarean. With a normal delivery, the midwife is the individual who decides whether to call the obstetrician for an urgent cesarean delivery. The woman's preference is either not expressed or not considered.

As a consequence, in this model, the private sector dummy captured not only the financial incentive to perform a cesarean but also a combination of the physician's preferences and the woman's preference. ${ }^{15}$ However, the financial incentive is clearly linked to what the woman

\footnotetext{
${ }^{14}$ We also used the hospital fixed-effects model as a robustness check. See Section 5.4 for more details.

${ }^{15}$ It may also capture any other effect due to the sector that is not taken into account by our extensive list of independent variables.
} 
can afford. Supplementary private health insurance makes the additional charge for the cesarean affordable as it provides reimbursement for the additional fees charged in hospitals of the private sector. At present, very disadvantaged women (i.e., those covered by the CMUC) do not have to pay this additional fee. Hence, for very poor women, the financial incentive to perform a cesarean does not depend on the additional fee. Indeed, private hospitals are not authorized to charge additional fees. For the low clinical risk subsample, we then compared the disadvantaged women between the sectors, which are in a similar situation with no financial incentive, but where in the private sector there is a combination of the physician's preference and the woman's preference. In the same way, we compared the better-off women between the sectors, where there is definitely a financial incentive to perform a cesarean for private hospitals and also where there is a combination of the physician's preference and the woman's preference in the private sector.

To capture the financial incentive, we then introduced the variable $I_{i j t}$, as a dummy variable for private supplementary insurance covering additional fees for obstetric procedures for woman $i$ in hospital $j$ in year $t$.

We did not have the individual information about private supplementary insurance enrollment. We then used the macro information from the Ministry of Health and based on the employment status (Table 1). For each employment status, we used the Ministry of Health's probability of enrollment. A high probability of enrollment was defined as a probability of enrollment for private health insurance greater than or equal to 0.8 and, inversely, a low probability of enrollment was defined as a probability of enrollment for private health insurance of less than 0.8 . The woman could be covered by her partner's health insurance. Therefore, her partner's private insurance enrollment was also considered. The dummy variable for private supplementary insurance enrollment was a single indicator defined as either the woman or her partner having an $80 \%$ or greater chance of having private insurance coverage for the birth. We assumed that for a low probability of enrollment for the household, this private insurance package did not include the additional cost for admission in a private hospital for a delivery. Therefore, the dummy variable of the crossed variable for the hospital sector and the dummy for a private supplementary insurance captured the financial incentives to perform a cesarean.

[Insert Table 1] 
To summarize, in this paper, we took into account the preferences of the woman and of the doctor in order to identify financial incentives as a factor impacting the treatment decision process. A cesarean birth may cause increased and perhaps unnecessary morbidity in a woman, as it is major surgery. However, obstetricians may actively seek to protect themselves from malpractice litigation. When a woman has a clinical risk factor, a cesarean can be a defensive measure to prevent complications during the delivery. Furthermore, for a woman with a clinical risk factor, the characteristics of the physician's practices may also determine whether they are more likely to perform a cesarean or a more complicated vaginal delivery. Therefore, the characteristics of a physician's practice and their choice to use defensive medicine cannot be disentangled. These points - defensive medicine preferences and practice characteristics - do not come into play for women who are at low risk. To do so, we used the French context and $i$ ) we ruled out the clinical risk determinants restricting the sample to women with low clinical risk; ${ }^{16}$ ii) we compared public and private hospitals; and iii) we focused on how the private insurance reimbursement affects the decision to perform a cesarean.

\section{Results}

\subsection{Patient and hospital factors}

Table A3 reports the effects of the individual and hospital control variables on the probability of cesarean deliveries. ${ }^{17}$ Different individual (including socioeconomic) and institutional characteristics are significant indicators of cesarean deliveries. Our results are in accordance with the findings in the literature. ${ }^{18}$

We also tested for a linear time trend for the seven-year period to identify any patterns of incidence for cesarean deliveries over the 2008-2014 period. Taking into account all the factors, we observed a non-significant overall trend.

Table 2 presents the effects of the hospital sector on a woman's probability of a cesarean delivery. Column 1 of Table 2 shows that, after controlling for age, parity, and medical risk factors, admission to a private hospital, as opposed to a public hospital, increases the probability of cesarean delivery. In addition to these epidemiologic factors, we also

\footnotetext{
${ }^{16}$ The definition of the low-risk subsample was based on the usual obstetric literature (Coulm et al., 2012).

${ }^{17}$ Table A3 is available in the Appendix with additional comments.

${ }^{18}$ As shown in more detail in Section 2.1.
} 
considered socioeconomic factors in column 2, and we find that private hospitals again have a higher rate of cesarean deliveries. In column 3, we also controlled for the hospital type and organization, and we find that, all else being equal, giving birth in a private hospital substantially increased the probability of cesarean delivery. By computing the odds ratio, we find that the probability of cesarean delivery rises by $79 \%$ in a private versus a public hospital (odds ratio $=1.79,95 \% \mathrm{CI}=[1.29-2.49]) .{ }^{19}$ However, this hospital sector effect may capture other determinants, as described above.

\section{[Insert Table 2]}

\subsection{Impact of the hospital sector}

The subsample of women with low risk is defined as women without any recorded clinical risk factors during both the pregnancy and the delivery process. The clinical risk subgroup includes all women with at least one recorded clinical risk factor. Table 3 presents the sector effect on the use of cesarean deliveries for both the high and the low medical risk subgroups in columns $1 \& 2$, respectively.

Irrespective of the other observed factors and the woman's risk level, private hospitals perform more cesarean deliveries than public hospitals. This result is obtained on each of the subsamples. For the high clinical risk sample, this can be explained by unobserved clinical factors, the risk aversion for malpractice liability, physician practice characteristics, medical recommendations, as well as the physicians' financial incentives. For the low clinical risk sample, this finding is a more accurate measure of physicians' responses to financial incentives. The physician's preference - potentially in association with the woman's preference - plays a role in the disparity we observed in the mode of delivery between the two sectors.

\section{[Insert Table 3]}

In the subsamples considered here, the treatment is in fact the result of two different initial delivery assignments (Figure 1): by a planned cesarean delivery or by a planned vaginal delivery. With a planned cesarean delivery, the additional payment requiring the presence of

\footnotetext{
${ }^{19}$ Similar magnitudes of difference between private and public hospitals have been reported in the literature (Lutomski et al., 2014; Salvador et al., 2009).
} 
the physician and the least hazardous delivery process are key factors. With an initial delivery assignment by planned cesarean, physicians can be expected to be more responsive to the financial incentive, and hence the financial impact can be expected to be more substantial. Therefore, we focus on the initial delivery assignment by planned cesarean. After adjusting for all of the variables including socioeconomic, institutional, and organizational factors, for a group of women with low clinical risk, we find that the hospital sector impacts the probability of planned cesarean delivery (column 3 of Table 3$).{ }^{20}$ For women with a low medical risk, the odds ratio of the sector effect on planned cesareans is $4.70(95 \% \mathrm{CI}=[2.69-8.19])$ whereas the odds ratio of the sector impact on all cesareans is $1.97(95 \% \mathrm{CI}=[1.48-2.61])$.

What about planned vaginal delivery? Women who requested a vaginal delivery in accordance with their obstetrician's advice in a private hospital are included in this subsample. This subsample also includes the situation where the physician-patient combination decision led to a planned vaginal delivery. Theoretically, a weaker effect of the hospital sector would be expected. Indeed, in the private sector, the additional payment requires the presence of the physician, but the physician cannot be sure that they will in fact be present at the time of the delivery. As before, we restricted the sample to the women with low clinical risk, i.e., women for whom defensive medicine is a marginal factor and we suppressed the planned cesarean cases. Holding all other covariates constant, we find a significant but weaker hospital sector effect, as theoretically expected (column 4 of Table 3 ).

\subsection{Impact of supplementary private health insurance}

The coefficients presented in Table 3 may still confound some unobserved factors, including the selection of patients and physicians across hospital types, with responses to financial incentives. To obtain a more accurate estimate of the latter, we exploited the fact that, even in a private hospital, from a physician's point of view, there are no financial incentives associated with patients who do not have supplementary health insurance. We used the "probability of non-affordability" as a "control" group to assess the financial incentives independently of other doctor characteristic factors such as their ability to control their

\footnotetext{
${ }^{20}$ Here, planned cesareans were compared with both unplanned cesareans and normal deliveries. However, the planned cesareans can only be compared with the normal deliveries, suppressing the urgent cesareans. Any urgent cesarean is an obstetrician's decision based on financial incentives or the occurrence of an unexpected factor unobserved by the econometrician. When we ran the model on the subsample excluding urgent cesarean deliveries, the results were largely the same (available upon request).
} 
schedule. To rule out the clinical risk determinants, we restricted the sample to the women with low clinical risk.

First of all, we find that, irrespective of the other observed factors, the mode of delivery does not depend on the probability of being covered by a private insurer (Table 4), except for the probability of a planned cesarean, where the cesarean rate is impacted significantly and negatively (column 2). Since private insurance does not represent a financial incentive for physicians in public hospitals, how should this result be interpreted? The supplementary private insurance variable is correlated to the socioeconomic status. As shown previously (Milcent and Zbiri, 2018), low socioeconomic women are more likely to have a cesarean, particularly because of poor prenatal follow-up.

Secondly, we assessed the baseline impact of being admitted in a private hospital on the probability of a cesarean (Private Hospital * Low insurance probability). We find that the rate of cesarean deliveries for women with low clinical risk is significantly higher in private compared to public hospitals (columns 1-3 of Table 4). This result may be explained by the other factors (physician and patient selection, fear of malpractice, etc.) that can drive the gap between the cesarean rate in public versus private hospitals. In this paper, we do not explain the entire difference, but we explore the impact of the financial incentive from additional payments on the difference in cesarean rates between statuses. To do so, we assessed how this probability varied for women with private insurance (Private hospital * High insurance probability). The difference with the baseline effect represents the measure of the impact of financial incentives. From column 1 of Table 4, we find a significant difference of $10 \%$ (Chisquare test $=2.96, \mathrm{p}$-value $=0.09)$. This result confirms that in the private sector, women at low risk but with a high probability of supplementary coverage have a higher probability of having a cesarean delivery.

The level of significance of $10 \%$ can be considered to be low, and it is hence questionable. This sample in fact deals with two initial delivery assignments that may impact the result. With an economically disadvantaged woman, without a private insurance package that covers the additional payment, there is no financial incentive to perform a planned or an unplanned cesarean. For women who pay the additional fee, there is clearly an incentive to perform a planned cesarean and to a much lesser extent to perform an unplanned cesarean. Indeed, in this case, the women have a low clinical risk. We then considered the following two probabilities. 
[Insert Table 4]

\section{Probability of a planned cesarean delivery}

For a number of reasons, as previously pointed out, a planned cesarean delivery is likely to be influenced by the hospital sector. For women with a low probability of supplementary private insurance, the impact of the hospital sector is significantly lower than for those with a high probability of supplementary insurance $($ column 2 of Table 4 , Chi-square test $=4.76, p$-value $=$ $0.03)$. The level of significance of $3 \%$ is then very convincing.

For low-risk women, the direct financial incentive plays a role in whether or not they have a cesarean delivery, albeit only when the woman has supplementary health insurance. These findings show that, aside from the effect of the other potential factors, the compensation scheme matters greatly in the choice of medical procedure.

\section{Probability of an unplanned cesarean delivery}

In this situation, the patient and the doctor together had opted for a planned vaginal delivery. ${ }^{21}$ This context includes the situation in which women schedule their vaginal delivery in concordance with the physician.

After removing planned cesarean deliveries, we explored the effect of the affordability of a cesarean for low-risk women for whom a vaginal delivery was planned initially (column 3 of Table 4). We observe no difference in the probability of having a cesarean between women with a high versus those with a low probability of supplementary private health insurance (Chi-square test $=0.16$, p-value $=0.69)$. We conclude that medical recommendation is an overriding factor. The physician's decision is also not significantly impacted by whether or not a woman has private health insurance. Additionally, having private health insurance does not affect a woman's preference when it comes to deciding on an urgent cesarean.

Thus, these findings confirm that, potentially in association with the woman's preference, the additional fees in the private sector (based on the additional room and board payment and the physicians' additional fees) only play a role in the disparity we observed in the mode of delivery between the two sectors when the affordability is ensured and when clinical aspects are not an overriding factor.

\footnotetext{
${ }^{21}$ With the risk of having an unplanned cesarean (as presented in Figure 1).
} 


\subsection{Robustness checks}

In this paper, we control for unobservable hospital heterogeneity by using hospital randomeffects. As previously explained, the Hausman test validates this econometric approach. As a sensitivity analysis, we use hospital fixed-effects for the results shown in Tables $2 \& 3$. There is strict collinearity between the hospital fixed-effects and the sector variable. We then compare the hospital fixed-effect coefficients for public-sector hospitals with those for private-sector hospitals. For each model, the sector difference is significant at $5 \%$ (results available upon request). ${ }^{22}$

As a sensitivity analysis, we also assess the sectors crossed with the private insurance enrollment effect (variables of interest), when using a hospital fixed-effects (11 hospital dummies) crossed with the probability of private insurance enrollment. ${ }^{23}$ There is strict collinearity between the hospital fixed-effects and the explanatory variables at the hospital level. We, therefore, use a two-step fixed-effects model. Clustered standard errors of the second stage are estimated by bootstrap due to the use of an estimated dependent variable. The results using the hospital fixed-effects specification are very similar to the previous findings based on hospital random-effects specification (Table A4 for results of Table 4).

One limitation of this paper is that we do not have the individual information on the private health insurance coverage for the additional cost of a cesarean. Overall, $95 \%$ of the population is covered by supplementary private health insurance. Private health insurance is standard for $95 \%$ of the population and a "no private insurance coverage" designation is the exception. However, being covered by private health insurance does not mean that the private insurance package fully reimburses the additional cost for a cesarean in the private sector. A certain number of non-advantaged and disadvantaged women are not covered or have poor cover for this additional cost. Most of the time, they enter into a special financial agreement with the private hospital that then charges less than the regular additional cost. Furthermore, the poorest CMU-C women are not covered for the additional cost of a cesarean. In France, a woman employed with a long-term contract has to enroll with the private health insurance

\footnotetext{
${ }^{22}$ We also considered hospital fixed effects crossed with time dummies. Clustered standard errors of the second stage were estimated by bootstrap due to the use of an estimated dependent variable. The results were unchanged (available upon request).

${ }^{23}$ As done previously, we also used the employment status of the woman and of her partner as a proxy for private insurance enrollment (Table 1).
} 
company proscribed by their employer, which usually covers common additional costs such as those for a cesarean. We impose a no private health insurance package to women in these three groups of employment status ("unemployed", "homemakers", and "not in the workforce") with a cut-off of 0.8 in the model (Table 4). The definition used so far (Table 4) could be an excessively restrictive definition of the "high probability of supplementary private insurance" group, thereby leading to some births associated with a financial incentive (albeit only a small number) to be included in the "low probability of supplementary private insurance group". Running the model with a cut-off of 0.7 imposed no coverage for the additional cost of a cesarean only for those who were unemployed, which amounts to the most disadvantaged group of women with the lowest probability of being covered for the additional costs of a cesarean. The results are shown in Table A5. We find that for the "low probability of being covered for cesarean extra cost" group, the sector has no effect on the probability of a cesarean being undertaken. However, the non-significant result might be due to the small number of women without private insurance coverage considered here. It is possible that the lack of statistical significance in column 2 of Table A5 for the coefficient on the variable "Private * Low prob. of suppl. private ins." is due to no overall effect or to a lack of statistical power to detect an effect given the small number of observations corresponding to that group.

\section{Conclusion}

We explore the effect of a financial incentive to perform cesarean deliveries as a factor that could explain part of the disparity we observe in the mode of delivery between the two sectors. We find that the financial incentive plays a role in the cesarean delivery for low-risk women, and this is all the more so when the patient has supplementary health insurance.

In terms of the extent of the effect, controlling for all factors, the probability of a cesarean delivery increases by $79 \%$ in private versus public hospitals. This result is in accordance with the previous literature. Furthermore, based on enrollment in private health insurance, this probability rises to $97 \%$ for women with a high probability of supplementary private coverage, but it rises to only $62 \%$ for women with a low probability of supplementary private coverage.

Different characteristics of the healthcare market may drive costly health behaviors. One of these is the hospital mode of financing. Payments to hospitals can result in financial incentives that may encourage healthcare providers, including hospitals and the physicians 
they employ, to perform some medical interventions over others. Most developed countries have recently adopted activity-based payment systems for the purpose of improving hospital efficiency as well as the quality and effectiveness of care. However, empirical evidence is scarce, except from the USA.

Cesarean deliveries are among the most common surgical procedures, and they account for a large proportion of the healthcare resources. They are also one of the medical practices studied most by economists because they are potentially responsive to a variety of economic forces including the payment source and financial incentives.

This study uses previously unexplored delivery data from a French administrative department to examine the effect of the hospital sector - private versus public — on the rate of cesarean deliveries, in the context of a single-payer healthcare finance system. The empirical analysis reveals that, after controlling for a large number of determinants for individual- and hospitallevel factors that may affect obstetric practices, the probability of a cesarean birth was higher in private hospitals than in public hospitals.

Despite the apparent similarity of funding for the private and public hospital sectors under a single-payer system, only private hospitals receive an additional payment from their patients for room and board, which are costs that are not reimbursed by the single-payer public health insurance system. These fees are, however, covered by private supplementary health insurers that help make care affordable for all patients irrespective of whether it is public or private and whether the delivery is cesarean or vaginal. As a result, a woman's preference for the mode of delivery is not dictated by financial accessibility. However, private supplementary health insurers perturb the public regulation set up by the reimbursement system of the singlepayer public health insurance system. Specifically, the availability of private health insurance affects medical practices in a market-driven public healthcare delivery system, including the creation of incentives for unnecessary practices. These private health insurance policies and choices may affect or prevent the implementation of public policies developed by policymakers for the benefit of society as a whole.

This result may apply to other healthcare systems such as, for instance, the development of private medical insurance in addition to the National Health Service as well as Medigap policies in addition to conventional Medicare. These forms of public healthcare funding, whether they are intended for widespread use (e.g., France, the UK, etc.) or more restricted 
use (e.g., Medicare in the USA), have been devised to address inequity in access to healthcare. However, the development of the portion of medical care supported by supplementary private health insurance may impair this social goal of equity. 


\section{Bibliographic references}

Allin, S., Baker, M., Isabelle, M., Stabile, M. (2015). Physician Incentives and the Rise in Csections: Evidence from Canada. National Bureau of Economic Research.

Allen, V. M., O'connell, C. M., Farrell, S. A., Baskett, T. F. (2005). Economic implications of method of delivery. American Journal of Obstetrics \& Gynecology, 193(1), 192-197.

Althabe, F., Sosa, C., Belizán, J. M., Gibbons, L., Jacquerioz, F., Bergel, E. (2006). Cesarean section rates and maternal and neonatal mortality in low-, medium-, and high-income countries: an ecological study. Birth, 33(4), 270-277.

Baker, L. C., Bundorf, M. K., Kessler, D. P. (2014). Vertical integration: hospital ownership of physician practices is associated with higher prices and spending. Health Affairs, 33(5), 756-763.

Barbetta, G. P., Turati, G., Zago, A. M. (2007). Behavioral differences between public and private not-for-profit hospitals in the Italian national health service. Health Economics, 16(1), 75-96.

Biørn, E., Hagen, T. P., Iversen, T., Magnussen, J. (2003). The effect of activity-based financing on hospital efficiency: a panel data analysis of DEA efficiency scores 1992-2000. Health Care Management Science, 6(4), 271-283.

Biørn, E., Hagen, T. P., Iversen, T., Magnussen, J. (2010). How different are hospitals' responses to a financial reform? The impact on efficiency of activity-based financing. Health Care Management Science, 13(1), 1-16.

Borden, J. P. (1988). An assessment of the impact of diagnosis-related group (DRG)-based reimbursement on the technical efficiency of New Jersey hospitals using data envelopment analysis. Journal of Accounting and Public Policy, 7(2), 77-96.

Brown, H. S. (1996). Physician demand for leisure: implications for cesarean section rates. Journal of Health Economics, 15(2), 233-242.

Chern, J. Y., Wan, T. T. (2000). The impact of the prospective payment system on the technical efficiency of hospitals. Journal of Medical Systems, 24(3), 159-172.

Clark, A. E., Milcent, C. (2011). Public employment and political pressure: The case of French hospitals. Journal of Health Economics, 30(5), 1103-1112. 
Cleary, R., Beard, R. W., Chapple, J., Coles, J., Griffin, M., Joffe, M., Welch, A. (1996). The standard primipara as a basis for inter-unit comparisons of maternity care. BJOG: An International Journal of Obstetrics \& Gynaecology, 103(3), 223-229.

Coulm, B., Le Ray, C., Lelong, N., Drewniak, N., Zeitlin, J., Blondel, B. (2012). Obstetric interventions for low-risk pregnant women in France: do maternity unit characteristics make a difference? Birth, 39(3), 183-191.

David, S., Mamelle, N., Rivière, O. (2001). Estimation of an expected caesarean section rate taking into account the case mix of a maternity hospital. Analysis from the AUDIPOG Sentinelle Network (France). BJOG: An International Journal of Obstetrics \& Gynaecology, 108(9), 919-926.

Dismuke, C. E., Sena, V. (1999). Has DRG payment influenced the technical efficiency and productivity of diagnostic technologies in Portuguese public hospitals? An empirical analysis using parametric and non-parametric methods. Health Care Management Science, 2(2), 107116.

Dubay, L., Kaestner, R., Waidmann, T. (1999). The impact of malpractice fears on cesarean section rates. Journal of Health Economics, 18(4), 491-522.

Ecker, J. L., Chen, K. T., Cohen, A. P., Riley, L. E., Lieberman, E. S. (2001). Increased risk of cesarean delivery with advancing maternal age: indications and associated factors in nulliparous women. American Journal of Obstetrics \& Gynecology, 185(4), 883-887.

Eggleston, K., Shen, Y. C., Lau, J., Schmid, C. H., Chan, J. (2008). Hospital ownership and quality of care: what explains the different results in the literature? Health Economics, 17(12), 1345-1362.

Fabbri, D., Monfardini, C. (2008). Style of practice and assortative mating: a recursive probit analysis of Caesarean section scheduling in Italy. Applied Economics, 40(11), 1411-1423.

Fuglenes, D., Øian, P., Kristiansen, I. S. (2009). Obstetricians' choice of cesarean delivery in ambiguous cases: is it influenced by risk attitude or fear of complaints and litigation? American Journal of Obstetrics \& Gynecology, 200(1), 48-e1.

Gibbons, L., Belizan, J. M., Lauer, J. A., Betran, A. P., Merialdi, M., Althabe, F. (2012). Inequities in the use of cesarean section deliveries in the world. American Journal of Obstetrics \& Gynecology, 206(4), 331-e1. 
Grant, D. (2009). Physician financial incentives and cesarean delivery: new conclusions from the healthcare cost and utilization project. Journal of Health Economics, 28(1), 244-250.

Gruber, J., Owings, M. (1996). Physician financial incentives and cesarean section delivery. The Rand Journal of Economics, 27(1), 99-123.

Gruber, J., Kim, J., Mayzlin, D. (1999). Physician fees and procedure intensity: the case of cesarean delivery. Journal of Health Economics, 18(4), 473-490.

Hafsteinsdottir, E. J. G., Siciliani, L. (2010). DRG prospective payment systems: refine or not refine? Health Economics, 19(10), 1226-1239.

Hammond, J. A. (2015). Does the presence of learners affect family medicine obstetric outcomes? Canadian Family Physician, 61(11), e504-e508.

Herwartz, H., Strumann, C. (2014). Hospital efficiency under prospective reimbursement schemes: an empirical assessment for the case of Germany. The European Journal of Health Economics, 15(2), 175-186.

Hyde, M. J., Modi, N. (2012). The long-term effects of birth by caesarean section: the case for a randomised controlled trial. Early Human Development, 88(12), 943-949.

Le Ray, C., Carayol, M., Zeitlin, J., Breart, G., Goffinet, F., PREMODA Study Group. (2006). Level of perinatal care of the maternity unit and rate of cesarean in low-risk nulliparas. Obstetrics \& Gynecology, 107(6), 1269-1277.

Linna, M. (1999). Health care financing reform and the productivity change in Finnish hospitals. Journal of Health Care Finance, 26(3), 83-100.

Linton, A., Peterson, M. R., Williams, T. V. (2004). Effects of maternal characteristics on cesarean delivery rates among US Department of Defense healthcare beneficiaries, 19962002. Birth, 31(1), 3-11.

Lutomski, J. E., Murphy, M., Devane, D., Meaney, S., Greene, R. A. (2014). Private health care coverage and increased risk of obstetric intervention. BMC Pregnancy and Childbirth, 14(1), 13.

Mazzoni, A., Althabe, F., Liu, N. H., Bonotti, A. M., Gibbons, L., Sánchez, A. J., Belizán, J. M. (2011). Women's preference for caesarean section: a systematic review and meta-analysis of observational studies. BJOG: an International Journal of Obstetrics \& Gynaecology, 118(4), 391-399. 
Menacker, F., Declercq, E., Macdorman, M. F. (2006). Cesarean delivery: background, trends, and epidemiology. Seminars in Perinatology, 30(5), 235-241.

Milcent, C., Rochut, J. (2009). Hospital Payment System and Medical Practice. Revue Economique, 60(2), 489-506.

Milcent, C., Zbiri, S. (2018). Prenatal care and socioeconomic status: effect on cesarean delivery. Health Economics Review, 8(1), 7.

Ministry of Health (2016). La complémentaire santé: acteurs, bénéficiaires, garanties. Panoramas de la DREES-Santé, 102.

Penn, Z., Ghaem-Maghami, S. (2001). Indications for caesarean section. Best Practice \& Research: Clinical Obstetrics \& Gynaecology, 15(1), 1-15.

Rogers, A. J., Rogers, N. G., Kilgore, M. L., Subramaniam, A., Harper, L. M. (2017). Economic Evaluations Comparing a Trial of Labor with an Elective Repeat Cesarean Delivery: A Systematic Review. Value in Health, 20(1), 163-173.

Roman, H., Blondel, B., Bréart, G., Goffinet, F. (2008). Do risk factors for elective cesarean section differ from those of cesarean section during labor in low risk pregnancies? Journal of Perinatal Medicine, 36(4), 297-305.

Salvador, J., Cano-Serral, G., Rodriguez-Sanz, M., Lladonosa, A., Borrell, C. (2009). Inequalities in caesarean section: influence of the type of maternity care and social class in an area with a national health system. Journal of Epidemiology and Community Health, 63(3), 259-261.

Sloan, F. A. (2000). Not-for-profit ownership and hospital behavior. Handbook of Health Economics, 1, 1141-1174.

Sommersguter-Reichmann, M. (2000). The impact of the Austrian hospital financing reform on hospital productivity: empirical evidence on efficiency and technology changes using a non-parametric input-based Malmquist approach. Health Care Management Science, 3(4), 309-321.

Souza, J. P., Gülmezoglu, A. M., Lumbiganon, P., Laopaiboon, M., Carroli, G., Fawole, B., Ruyan, P. (2010). Caesarean section without medical indications is associated with an increased risk of adverse short-term maternal outcomes: the 2004-2008 WHO Global Survey on Maternal and Perinatal Health. BMC Medicine, 8(1), 71. 
Villar, J., Carroli, G., Zavaleta, N., Donner, A., Wojdyla, D., Faundes, A., Velazco, A., Bataglia, V., Langer, A., Narváez, A., Valladares, E., Shah, A., Campodónico, L., Romero, M., Reynoso, S., de Pádua, K. S., Giordano, D., Kublickas, M. (2007). Maternal and neonatal individual risks and benefits associated with caesarean delivery: multicentre prospective study. British Medical Journal, 335(7628), 1025.

Widmer, P. K. (2015). Does prospective payment increase hospital (in) efficiency? Evidence from the Swiss hospital sector. The European Journal of Health Economics, 16(4), 407-419.

Yang, Y. T., Mello, M. M., Subramanian, S. V., Studdert, D. M. (2009). Relationship between malpractice litigation pressure and rates of cesarean section and vaginal birth after cesarean section. Medical Care, 47(2), 234.

Yee, L. M., Liu, L. Y., Grobman, W. A. (2017). Obstetrician call schedule and obstetric outcomes among women eligible for a trial of labor after cesarean. American Journal of Obstetrics \& Gynecology, 216(1), 75-e1.

Zbiri, S., Rozenberg, P., Goffinet, F., Milcent, C. (2018). Cesarean delivery rate and staffing levels of the maternity unit. PloS One, 13(11), e0207379. 


\section{Figures}

Figure 1. Identification process from the initial delivery assignment to the actual mode of delivery.

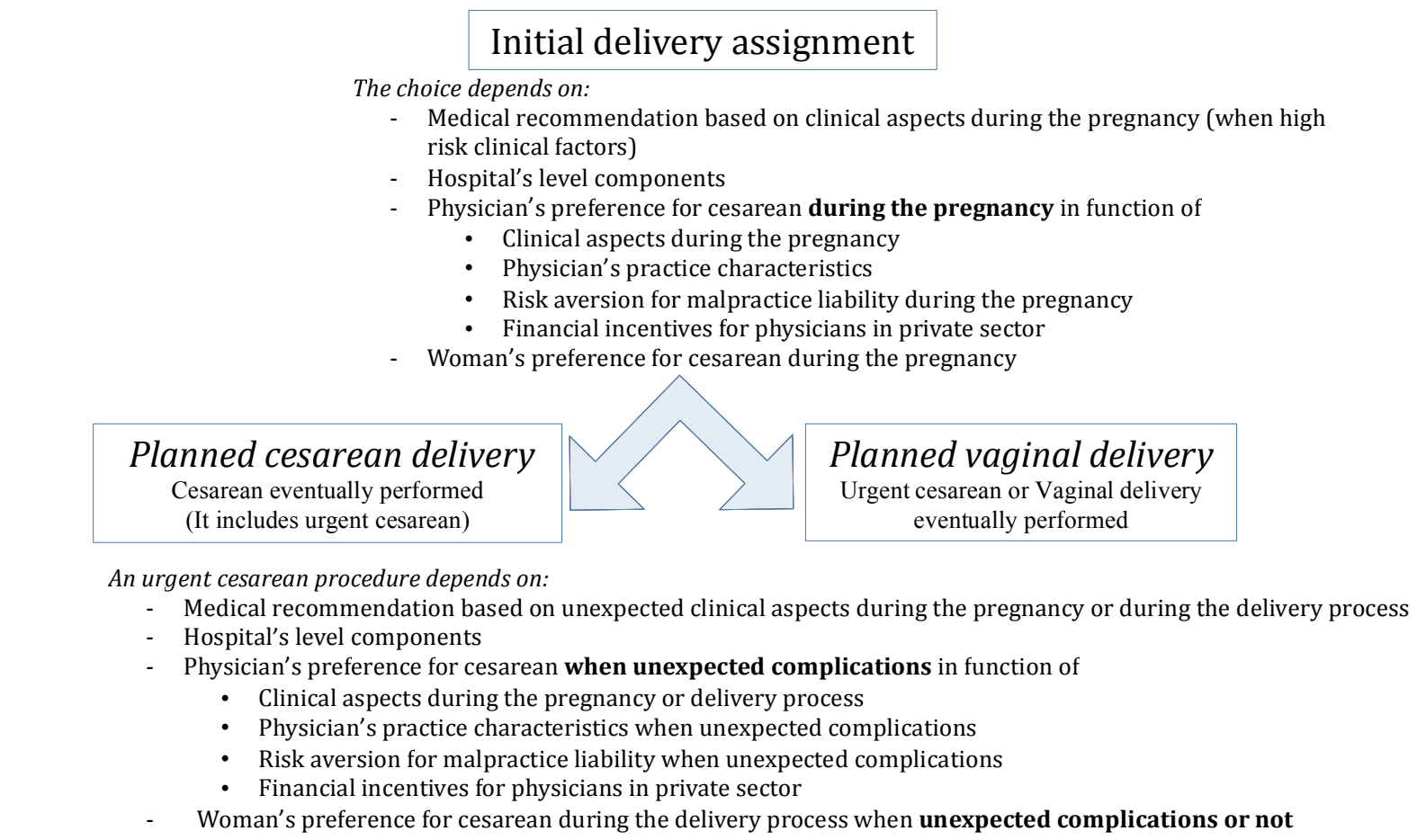

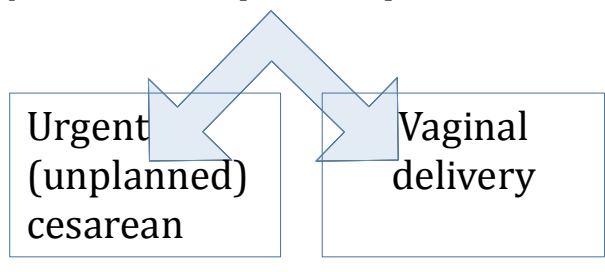




\section{Tables}

Table 1. Rates of enrollment by supplementary private insurance according to the employment status.

\begin{tabular}{lll}
\hline & Overall rate & Rate excluding CMU-C \\
\hline $\begin{array}{l}\text { High probability of enrollment } \\
\begin{array}{l}\text { Working Employed people } \\
\text { (including those on parental leave) }\end{array}\end{array}$ & $96 \%$ & $94 \%$ \\
$\begin{array}{l}\text { Retirees } \\
\text { Students and apprentices }\end{array}$ & $95 \%$ & $94 \%$ \\
Low probability of enrollment & $95 \%$ & $92 \%$ \\
Homemakers & $91 \%$ & $71 \%$ \\
Unemployed people (on the labor market) & $86 \%$ & $61 \%$ \\
Not in the labor force (including housewives) & $86 \%$ & $73 \%$ \\
\hline
\end{tabular}

Note: The economically disadvantaged people are eligible for a public supplementary insurance playing an equivalent role as a private supplementary insurance, called the CMU-C. However, this public supplementary insurance does not cover extra costs defined here for a cesarean in a private hospital. Therefore, we use the coverage rate excluding the CMU-C to create the private supplementary insurance variable $\left(I_{i j t}\right)$.

Data source: French Ministry of Health (the Ministère de la Santé, DREES), 2012. 
Table 2. Effects of hospital sector on cesarean deliveries. Multilevel logit models (coefficient estimates).

\begin{tabular}{|c|c|c|c|}
\hline $\begin{array}{r}\text { Sample: } \\
\text { Dependent variable: }\end{array}$ & $\begin{array}{l}\text { All women } \\
\operatorname{Pr}(\text { Cesarean }) \\
1\end{array}$ & $\begin{array}{l}\text { All women } \\
\operatorname{Pr}(\text { Cesarean }) \\
2\end{array}$ & $\begin{array}{l}\text { All women } \\
\operatorname{Pr}(\text { Cesarean }) \\
3\end{array}$ \\
\hline $\begin{array}{l}\text { Time } \\
\text { Trend }\end{array}$ & $\begin{array}{l}0.003 \\
(0.014)\end{array}$ & $\begin{array}{l}0.002 \\
(0.015)\end{array}$ & $\begin{array}{l}0.001 \\
(0.013)\end{array}$ \\
\hline $\begin{array}{l}\text { Hospital sector } \\
\text { Private }\end{array}$ & $\begin{array}{l}0.418^{* * *} \\
(0.117)\end{array}$ & $\begin{array}{l}0.460^{* * *} \\
(0.120)\end{array}$ & $\begin{array}{l}0.582^{* * *} \\
(0.168)\end{array}$ \\
\hline $\begin{array}{l}\text { Demographic control variables } \\
\text { Medical control variables } \\
\text { Socioeconomic control variables } \\
\text { Hospital control variables }\end{array}$ & $\begin{array}{l}\text { Yes } \\
\text { Yes } \\
\text { No } \\
\text { No }\end{array}$ & $\begin{array}{l}\text { Yes } \\
\text { Yes } \\
\text { Yes } \\
\text { No }\end{array}$ & $\begin{array}{l}\text { Yes } \\
\text { Yes } \\
\text { Yes } \\
\text { Yes }\end{array}$ \\
\hline Observations $(N)$ & 58,645 & 58,645 & 58,645 \\
\hline
\end{tabular}

Data source: PCS, SAE, Yvelines district (France), 2008-2014.

Note: Robust standard errors clustered at the hospital level in parentheses. $* * *=1 \%$ significance level, $* *=5 \%, *=10 \%$. All regressions use the main sample with complete socioeconomic data. Control variables include intercept; for demographics: age and parity; for medical risk factors: previous cesarean, diabetes, hypertension, eclampsia or preeclampsia, fetal growth restriction, placental disorder, other obstetric pathology, plurality, term at delivery, fetal presentation, induced labor, and birthweight; for socioeconomic status: woman's status of the couple, education, job, and employment status, and her partner's job and employment status; and for hospital characteristics: equipment level, teaching status, obstetrician availability, day of delivery, size, and numbers of full-time midwives, obstetricians, and anesthetists per occupied bed. 
Table 3. Effects of hospital sector on cesarean deliveries, for different subgroups of women. Multilevel logit models (coefficient estimates).

\begin{tabular}{|c|c|c|c|c|}
\hline Sample: & $\begin{array}{l}\text { High medical } \\
\text { risk }\end{array}$ & $\begin{array}{l}\text { Low medical } \\
\text { risk }\end{array}$ & $\begin{array}{l}\text { Low medical } \\
\text { risk }\end{array}$ & $\begin{array}{l}\text { Low medical } \\
\text { risk \& planned } \\
\text { cesareans } \\
\text { deleted }\end{array}$ \\
\hline \multirow[t]{2}{*}{ Dependent variable: } & $\operatorname{Pr}($ Cesarean) & $\operatorname{Pr}($ Cesarean) & $\begin{array}{l}\text { Pr (Planned } \\
\text { cesarean) }\end{array}$ & $\begin{array}{l}\text { Pr }(\text { Unplanned } \\
\text { cesarean) }\end{array}$ \\
\hline & 1 & 2 & 3 & 4 \\
\hline $\begin{array}{l}\text { Time } \\
\text { Trend }\end{array}$ & $\begin{array}{l}-0.001 \\
(0.016)\end{array}$ & $\begin{array}{l}0.006 \\
(0.012)\end{array}$ & $\begin{array}{l}0.041^{* *} \\
(0.019)\end{array}$ & $\begin{array}{l}-0.011 \\
(0.013)\end{array}$ \\
\hline $\begin{array}{l}\text { Hospital sector } \\
\text { Private }\end{array}$ & $\begin{array}{l}0.633^{* * *} \\
(0.167)\end{array}$ & $\begin{array}{l}0.677^{* * *} \\
(0.145)\end{array}$ & $\begin{array}{l}1.547^{* * *} \\
(0.284)\end{array}$ & $\begin{array}{l}0.477^{* * *} \\
(0.084)\end{array}$ \\
\hline Demographic control variables & Yes & Yes & Yes & Yes \\
\hline Medical control variables & Yes & Yes & Yes & Yes \\
\hline Socioeconomic control variables & Yes & Yes & Yes & Yes \\
\hline Hospital control variables & Yes & Yes & Yes & Yes \\
\hline Observations $(N)$ & 28,312 & 30,333 & 30,333 & 29,088 \\
\hline
\end{tabular}

Data source: PCS, SAE, Yvelines district (France), 2008-2014.

Note: Robust standard errors clustered at the hospital level in parentheses. $* * *=1 \%$ significance level, $* *=5 \%, *=10 \%$. All regressions use the main sample with complete socioeconomic data. Control variables include intercept; for demographics: age and parity; for medical risk factors: previous cesarean, diabetes, hypertension, eclampsia or preeclampsia, fetal growth restriction, placental disorder, other obstetric pathology, plurality, term at delivery, fetal presentation, induced labor, and birth weight; for socioeconomic status: woman's status of the couple, education, job, and employment status, and her partner's job and employment status; and for hospital characteristics: equipment level, teaching status, obstetrician availability, day of delivery, size, and numbers of full-time midwives, obstetricians, and anesthetists per occupied bed. 
Table 4. Effects of supplementary private health insurance on cesarean deliveries. Multilevel logit models (coefficient estimates).

\begin{tabular}{|c|c|c|c|}
\hline \multirow{3}{*}{ Dependent variable: } & $\begin{array}{l}\text { Low medical } \\
\text { risk }\end{array}$ & $\begin{array}{l}\text { Low medical } \\
\text { risk } \\
\text { deleted }\end{array}$ & $\begin{array}{l}\text { Low medical risk \& } \\
\text { planned cesareans }\end{array}$ \\
\hline & $\begin{array}{l}\operatorname{Pr}(\text { Cesarean }) \\
\text { cesarean })\end{array}$ & $\begin{array}{l}\text { Pr (Planned } \\
\text { cesarean) }\end{array}$ & Pr (Unplanned \\
\hline & 1 & 2 & 3 \\
\hline \multicolumn{4}{|l|}{ Time } \\
\hline Trend & $\begin{array}{l}0.006 \\
(0.012)\end{array}$ & $\begin{array}{l}0.041^{* *} \\
(0.019)\end{array}$ & $\begin{array}{l}-0.011 \\
(0.013)\end{array}$ \\
\hline \multicolumn{4}{|l|}{ Supplementary private health insurance } \\
\hline $\begin{array}{l}\text { High prob. of suppl. private ins. } \\
\text { (woman or her partner) }\end{array}$ & Reference & Reference & Reference \\
\hline $\begin{array}{l}\text { Low prob. of suppl. private ins. } \\
\text { (woman and her partner) }\end{array}$ & $\begin{array}{l}0.043 \\
(0.100)\end{array}$ & $\begin{array}{l}0.412^{* *} \\
(0.199)\end{array}$ & $\begin{array}{l}-0.073 \\
(0.098)\end{array}$ \\
\hline \multicolumn{4}{|c|}{ Crossed variables for hospital sector and supplementary private health insurance } \\
\hline $\begin{array}{l}\text { Private * High prob. of suppl. private ins. } \\
\text { (woman or her partner) }\end{array}$ & $\begin{array}{l}0.679^{* * *} \\
(0.145)\end{array}$ & $\begin{array}{l}1.554^{* * *} \\
(0.282)\end{array}$ & $\begin{array}{l}0.476^{* * *} \\
(0.084)\end{array}$ \\
\hline $\begin{array}{l}\text { Private * Low prob. of suppl. private ins. } \\
\text { (woman and her partner) }\end{array}$ & $\begin{array}{l}0.481^{* *} \\
(0.201)\end{array}$ & $\begin{array}{l}0.824^{*} \\
(0.447) \\
\end{array}$ & $\begin{array}{l}0.536^{* * *} \\
(0.147)\end{array}$ \\
\hline Demographic control variables & Yes & Yes & Yes \\
\hline Medical control variables & Yes & Yes & Yes \\
\hline Socioeconomic control variables & Yes & Yes & Yes \\
\hline Hospital control variables & Yes & Yes & Yes \\
\hline Observations $(N)$ & 30,333 & 30,333 & 29,088 \\
\hline
\end{tabular}

Data source: PCS, SAE, Yvelines district (France), 2008-2014.

Note: Robust standard errors clustered at the hospital level in parentheses. $* * *=1 \%$ significance level, $* *=5 \%, *=10 \%$. All regressions use the main sample with complete socioeconomic data. Control variables include intercept; for demographics: age and parity; for medical risk factors: previous cesarean, diabetes, hypertension, eclampsia or preeclampsia, fetal growth restriction, placental disorder, other obstetric pathology, plurality, term at delivery, fetal presentation, induced labor, and birth weight; for socioeconomic status: woman's status of the couple, education, job, and employment status, and her partner's job and employment status; and for hospital characteristics: equipment level, teaching status, obstetrician availability, day of delivery, size, and numbers of full-time midwives, obstetricians, and anesthetists per occupied bed. 